\title{
Best Possible Medication Histories by Registered Pharmacy Technicians in Ambulatory Care
}

\author{
Ida-Maisie Famiyeh, Neil Jobanputra, and Lisa M McCarthy
}

Can J Hosp Pharm. 2021;74(2):149-55

\section{INTRODUCTION}

Medication reconciliation is a formal process involving collaboration among health care professionals, patients, and their families or caregivers to communicate patients' accurate and comprehensive medication information across transitions of care. ${ }^{1}$ It is a strategy for reducing unintentional medication discrepancies, which occur when there is a change - not intended by the original prescriber - in medications taken by patients between one setting (e.g., home) and another (e.g., hospital)..$^{2-6}$ Unintentional medication discrepancies lead to inaccurate medication information, which could potentially lead to adverse drug events and outcomes (e.g., hospital readmissions).

Medication reconciliation requires that an accurate list of a patient's medications (i.e., a best possible medication history $[\mathrm{BPMH}])$ be obtained and compared with medications ordered in the health care institution to allow identification and resolution of any discrepancies. Obtaining a BPMH involves gathering information from multiple sources (e.g., community pharmacy, government claims, interviews) and using it to develop a comprehensive medication list. ${ }^{7}$ Preparing the BPMH is the first step in the medication reconciliation process; without it, medication reconciliation cannot take place. ${ }^{1,8}$

To optimize use of limited health system resources, several studies have described the use of registered pharmacy technicians (RPhTs) to obtain BPMHs in tertiary and acute care institutions ${ }^{9-11}$; however, the model has not yet been explored in the ambulatory care context. In ambulatory care, implementing patient safety initiatives, including medication reconciliation, presents unique challenges. Unlike patients admitted to hospital for an overnight stay, patients in ambulatory settings often visit their health care providers and return home the same day. When follow-up is scheduled, it may be weeks or months after the original visit.

The RPhT-conducted BPMH program described here was developed at Women's College Hospital, Canada's only academic ambulatory hospital. Until May 2017, Women's College Hospital lacked a formal BPMH and systematic medication reconciliation program in many of its clinical areas. Having an established, institution-wide, interprofessional medication reconciliation program (including a formal BPMH process) was an institutional goal linked to Accreditation Canada's required organizational practices, which at the time required a documented and coordinated medication reconciliation program in at least 1 ambulatory patient care area. ${ }^{12}$ This paper describes our experience developing and implementing a program that features RPhT-conducted BPMHs in an ambulatory care institution.

\section{METHODS}

The Template for Intervention Description and Replication (TIDieR) checklist ${ }^{13}$ was used as a guide to describing the RPhT-conducted BPMH program.

\section{Setting}

The RPhT-conducted BPMH program was implemented in the preadmission clinic (PAC) of the institution's surgical services department, which operates only on weekdays. PAC staff members schedule patients for an in-person or telephone assessment, which occurs before their surgery date. The BPMH program was implemented only for in-person appointments. Before piloting the program, a process map of the existing workflow (Figure 1) was created to determine the stage at which BPMHs would be conducted. After testing different flows, a process was finalized that worked well for both patients and staff (Figure 2).

\section{Development of Written Training Materials}

Written training materials were developed through discussions with the pharmacy and surgery team and using resources from the Institute for Safe Medication Practices Canada (ISMP Canada). ${ }^{14}$ The content included a description of the medication reconciliation process, the rationale 
for medication reconciliation in ambulatory care, comprehensive steps to obtaining an accurate BPMH, a description of the patient interview approach, and tips.

\section{Training}

Four RPhTs were trained by one pharmacist (I.M.F.) to obtain BPMHs. First, the RPhTs completed a BPMH workshop for pharmacy technicians, an external program offered by ISMP Canada. ${ }^{14}$ In addition to this off-site certification program, the RPhTs underwent a 2- to 7-week training program developed by the institution. The training program was modelled after a program at another institution, ${ }^{15}$ adapted for the ambulatory care setting. The RPhTs were trained one at a time, and the training consisted of 5 main stages.

Stage 1, RPhT reviews written training materials: The RPhT reviewed the written training materials about medication reconciliation and the RPhT's role in the process.

Stage 2, pharmacist conducts BPMH while RPhTobserves: To model patient interviewing, the pharmacist (I.M.F.) conducted at least $15 \mathrm{BPMH}$ interviews (over 1-3 days), with direct observation by the RPhT. The same pharmacist conducted each set of interviews and obtained patient consent before observation by the RPhT. After each interview, the pharmacist and the RPhT discussed the encounter and

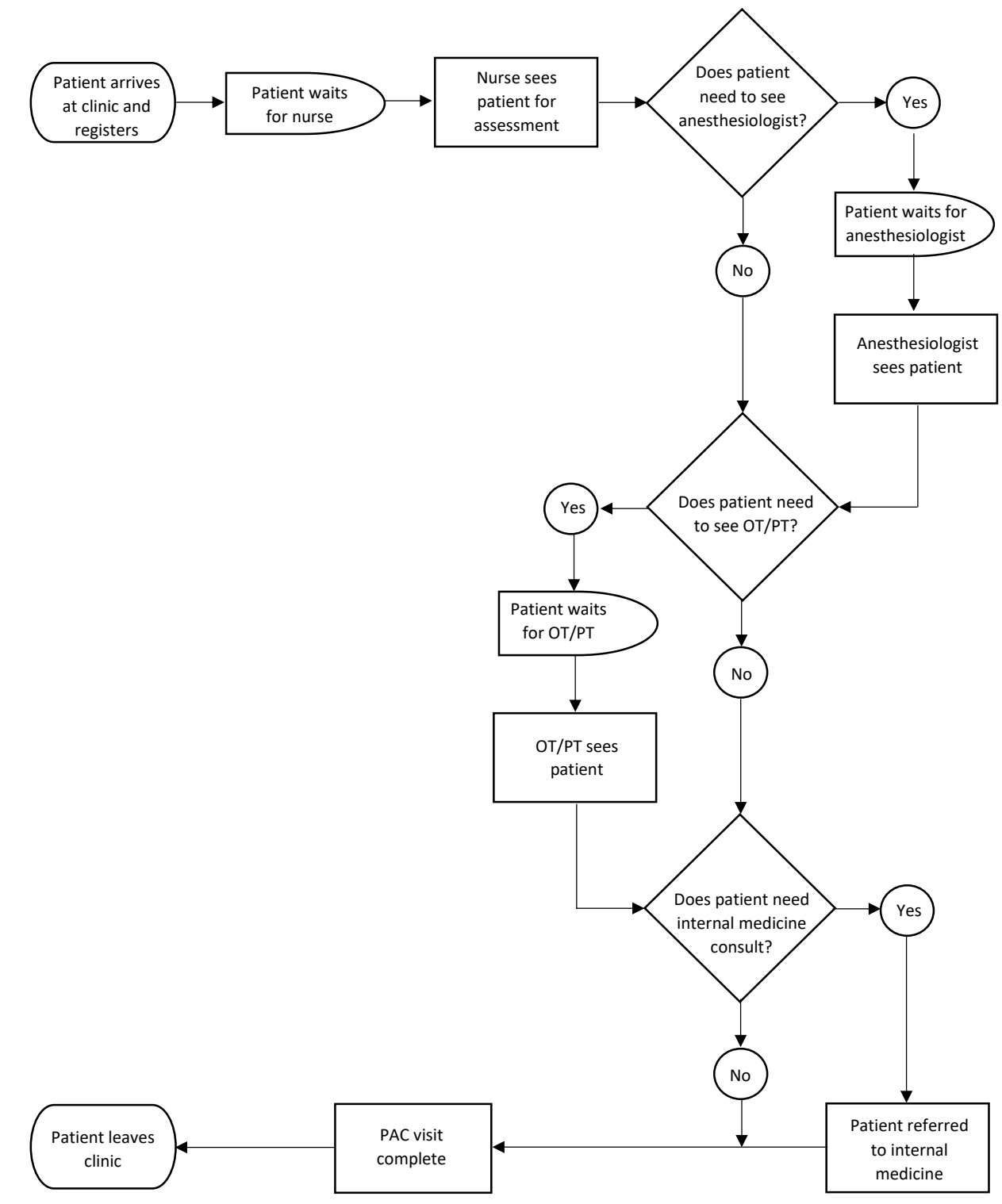

LEGEND $\bigcirc$ Start/End $\square$ Delay $\square$ Process $\bigcirc$ Connector $\$ Decision

FIGURE 1. Preadmission clinic (PAC) flow before implementation of the best possible medication history (BPMH) program conducted by registered pharmacy technicians (RPhTs). OT = occupational therapist, PT = physiotherapist. 
addressed any questions that the RPhT had. The minimum number of interviews to be observed was chosen arbitrarily; after observation of 15 interviews, the RPhT was given the choice to either observe more interviews or proceed to the next stage of training.

Stage 3, RPhT conducts BPMH while pharmacist observes: Each RPhT was required to conduct at least 25 patient interviews under direct supervision of the pharmacist. The pharmacist made notes during the interview and provided verbal feedback to the RPhT after each one. After the minimum 25 interviews, the RPhT and pharmacist discussed proceeding to independent patient interviews (i.e., without direct observation by the pharmacist). Factors that played a role in this decision included demonstration of verbal and nonverbal communication skills, adherence to the BPMH interview guide (Appendix 1, available at https://cjhp.journals. publicknowledgeproject.org/index.php/cjhp/issue/view/204), and the RPhT's self-assessed readiness to proceed.

Stage 4, RPhT independently conducts BPMHs (without pharmacist observation), and pharmacist audits all $B P M H s$ for accuracy: After each independently conducted interview, the pharmacist audited the BPMH documentation form (Appendix 2, available at https://cjhp.journals .publicknowledgeproject.org/index.php/cjhp/issue/view/204)

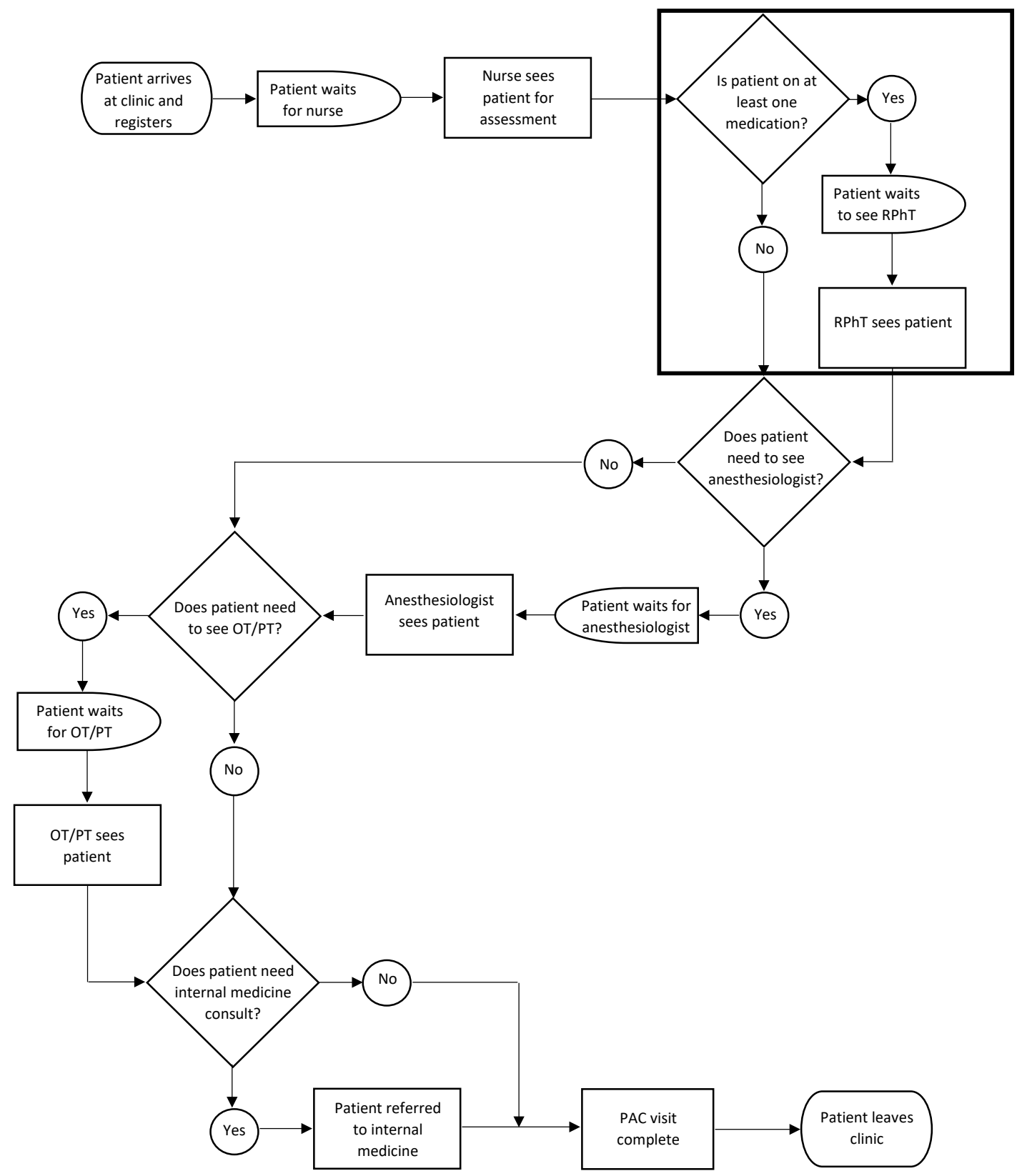

FIGURE 2. Preadmission clinic (PAC) flow after implementation of the best possible medication history (BPMH) program conducted by registered pharmacy technicians (RPhTs). Section enclosed in a thick-line box reflects process change relative to Figure 1. See legend in Figure 1 for explanations of box shapes. OT = occupational therapist, PT = physiotherapist. 
to ensure that the RPhT had completed all relevant sections. Specifically, the pharmacist checked for the following elements:

- medication name, specifically including the generic name (accurately spelled) and strength

- dose, dosage form, route, frequency, patient-reported indication (if known)

- allergies

- antibiotic use in previous 3 months

- comments on adherence

- history of analgesic medications (e.g., nonsteroidal anti-inflammatories, opioids)

- community pharmacy information

- medication information sources (at least 2)

- RPhT name, designation, signature, date

To be certified as BPMH-trained, the RPhT had to complete 75 consecutive BPMHs without the pharmacist finding any inaccuracies.

Stage 5, RPhT independently conducts BPMHs, with random audits by pharmacist when needed: Once certified as $\mathrm{BPMH}$-trained, the RPhT conducted BPMHs independently, with random audits by the pharmacist for quality assurance. Inaccuracies identified during these random audits were brought to the attention of the RPhT, with discussions on strategies to minimize errors.

\section{Documentation Tool}

An essential component of the BPMH is accurate documentation of a patient's medication list, as verified against secondary information sources; this is what makes a $\mathrm{BPMH}$ more reliable than a traditional medication history. A BPMH documentation form specific to surgical services (Appendix 2) was created with guidance from Safer Healthcare Now, ${ }^{1}$ as well as discussion among the pharmacy and surgery teams. After every $\mathrm{BPMH}$, the RPhT signed the completed documentation form (Appendix 2) and stored it in the patient's paper chart (at the time of program implementation, the PAC did not have electronic medical records).

\section{Outcome Measures}

The main outcome measure was BPMH compliance, which was defined as the proportion of eligible patients whose BPMHs were completed by an RPhT:

\section{Total number of patients with completed BPMH}

Total number of patients eligible for BPMH

Before implementing the program, the proportion of eligible patients who received a complete BPMH was $0 \%$, and the aim was to increase the proportion to $80 \%$.

\section{The BPMH Process}

The RPhT-conducted BPMH program consisted of 3 key phases and involved trained RPhTs, pharmacists, and nurses, as follows.
Phase 1, nurse refers eligible patients to RPhT: Individual patients who were booked for an in-person assessment at the PAC first had a consultation with a nurse. During this consultation, the nurse assessed patients' eligibility for a $\mathrm{BPMH}$ before referring them to the RPhT. Patients were eligible for a BPMH if they were taking more than 1 medication (i.e., prescription medications, over-the-counter products, vitamins, herbals, supplements).

Phase 2, RPhT conducts a BPMH in the PAC: The RPhT performed BPMH interviews from Monday to Friday for eligible patients referred by the nursing staff. For patients with medication coverage through the provincial insurance program, the RPhT accessed an online portal before interviewing the patient and printed a preliminary list of prescribed medications covered through this program. For patients without medication coverage through the provincial insurance program, the RPhT did not contact any community pharmacies before conducting the BPMH interview, because a patient's preferred community pharmacy (or pharmacies) was not known until the time of the assessment visit. After each interview, the RPhT contacted the patient's medication information sources (gathered during the encounter) to verify the information obtained.

Phase 3, pharmacist tracks BPMH compliance: The pharmacist conducted monthly tracking of BPMHs and calculated adherence.

\section{Integrating RPhT-Conducted BPMH within Medication Reconciliation Process}

After obtaining the BPMH and completing the documentation, the RPhT used the information to identify patients who would benefit from medication reconciliation upon discharge, according to prespecified criteria (Appendix 3, available https://cjhp.journals.publicknowledgeproject.org/ index.php/cjhp/issue/view/204). During the first 2 months, the RPhT practised identifying these eligible patients but did not track them, because the information was not required until the medication reconciliation component of the program was implemented. Once the medication reconciliation component was in effect, the RPhT tracked eligible patients, which allowed the pharmacist to conduct medication reconciliation.

For each patient, the surgical procedure was performed approximately 7 days after the PAC consult. On the day of surgery, before the procedure, nursing staff used the documented $\mathrm{BPMH}$ to capture any changes to the patient's medications.

\section{RESULTS}

During the evaluation period (May 2017 to April 2018), a total of 2185 patients were identified as being eligible for a BPMH. Of these, 2001 patients (92\%) had a BPMH completed by one of the trained RPhTs (Table 1), which exceeded the target $80 \%$. A mean of 9 BPMH interviews 
were conducted per day (standard deviation [SD] 3.7; minimum 1, maximum 19). A total of 184 interviews (8\%), could not be completed for various reasons: patient not referred by nursing staff (51\% [93/184]), limited staffing $(22 \%$ [41/184]), missed appointment (10\% [18/184]), and other reasons $(17 \%$ [32/184]). The mean time spent (including review of the chart and consultation with other sources to obtain additional information) was 10 minutes (SD 4.8; minimum 4, maximum 30 ). Approximately $33 \%$ of patients $(536 / 1646)$ were identified by RPhTs as potentially benefiting from medication reconciliation by a pharmacist upon discharge.

The RPhTs all had more than 10 years of practice experience but varied in their experience conducting BPMHs (minimum none, maximum 4 years). Variations in other aspects of the training process are detailed in Table 2.

\section{DISCUSSION}

Prior studies have explored RPhT-conducted BPMHs as part of the medication reconciliation process ${ }^{16-18}$; however, to our knowledge, this project is the first to describe the application of RPhT-conducted BPMHs in an academic ambulatory setting. The surgical services department of the ambulatory care hospital was chosen because it is an area with frequent transitions in care (i.e., preadmission consults on one day, followed by surgery and discharge on a different day). Each transition point represents an opportunity for unintentional medication discrepancies to occur. Before implementation of the RPhT-conducted BPMH program, traditional medication histories were gathered by nurses during PAC appointments, but secondary sources of information were not used for verification. The institution's priority was to implement

TABLE 1. Eligible Patients with BPMH Completed per Month

\begin{tabular}{|c|c|c|c|c|c|}
\hline $\begin{array}{l}\text { Month } \\
2017\end{array}$ & $\begin{array}{l}\text { No. of Patients } \\
\text { Eligible for BPMH }\end{array}$ & \multicolumn{2}{|c|}{$\begin{array}{l}\text { No. (\%) of BPMHs } \\
\text { Completed by RPhT }\end{array}$} & \multicolumn{2}{|c|}{$\begin{array}{l}\text { No. }(\%) \text { of Patients Identified } \\
\text { for Medication Reconciliation }\end{array}$} \\
\hline May & 222 & 180 & (81) & \multicolumn{2}{|c|}{ Data not available } \\
\hline June & 194 & 175 & (90) & \multicolumn{2}{|c|}{ Data not available } \\
\hline July & 194 & 179 & (92) & 18 & $(10)$ \\
\hline August & 169 & 158 & (93) & 24 & (15) \\
\hline September & 147 & 140 & (95) & 48 & (34) \\
\hline October & 152 & 142 & (93) & 32 & (22) \\
\hline November & 202 & 182 & (90) & 43 & (24) \\
\hline December & 96 & 93 & (97) & 38 & (41) \\
\hline \multicolumn{6}{|l|}{2018} \\
\hline January & 207 & 177 & (85) & 62 & (35) \\
\hline February & 205 & 187 & (91) & 89 & (48) \\
\hline March & 204 & 198 & (97) & 90 & (45) \\
\hline April & 193 & 190 & (98) & 92 & (48) \\
\hline Total & 2185 & 2001 & (92) & 536 & $\left(32^{*}\right)$ \\
\hline
\end{tabular}

$\mathrm{BPMH}=$ best possible medication history, $\mathrm{RPhT}=$ registered pharmacy technician.

${ }^{*}$ The RPhT assessment of patients for medication reconciliation eligibility began in July 2017. Between July 2017 and April 2018, there were 1646 patients for whom a BPMH was completed by the RPhT, which served as the denominator for calculating the proportion of patients identified as potentially benefiting from medication reconciliation.

TABLE 2. Characteristics and Training Cycles of Registered Pharmacy Technicians

\begin{tabular}{|c|c|c|c|c|c|c|c|}
\hline \multirow[b]{2}{*}{ RPhT } & \multicolumn{2}{|c|}{ Experience (yrs) } & \multirow[b]{2}{*}{$\begin{array}{l}\text { Length of } \\
\text { BPMH Training } \\
\text { (wks) }\end{array}$} & \multirow[b]{2}{*}{$\begin{array}{l}\text { No. of Pharmacist } \\
\text { Interviews Obs. } \\
\text { by RPhT }\end{array}$} & \multirow[b]{2}{*}{$\begin{array}{c}\text { No. of RPhT } \\
\text { Interviews Obs. } \\
\text { by Pharmacist }\end{array}$} & \multirow[b]{2}{*}{$\begin{array}{c}\text { Attempts } \\
\text { Conducting } \\
75 \text { Consec. BPMHs }{ }^{a}\end{array}$} & \multirow[b]{2}{*}{$\begin{array}{l}\text { No. of } \\
\text { Interviews } \\
\text { Audited }\end{array}$} \\
\hline & $\begin{array}{c}\text { Total } \\
\text { in Practice }\end{array}$ & $\begin{array}{l}\text { With } \\
\text { BPMH }\end{array}$ & & & & & \\
\hline 1 & $>25$ & 0 & 5 & 25 & 38 & 3 & 110 \\
\hline 2 & 17 & 0 & 7 & 19 & 43 & 4 & 125 \\
\hline 3 & 10 & 2 & 3 & 15 & 27 & 1 & 92 \\
\hline 4 & 18 & 4 & 2 & 15 & 28 & 0 & 75 \\
\hline
\end{tabular}

$\mathrm{BPMH}=$ best possible medication history, Consec. $=$ consecutive, Obs. $=$ observed, $\mathrm{RPhT}=$ registered pharmacy technician.

aWithout error. 
an RPhT-conducted BPMH program that would be easily integrated into existing workflow, with minimal disruptions. RPhTs are in a unique position to perform BPMHs because they are knowledgeable about medication names, formulations, strengths, and dosing schedules. ${ }^{19}$ The use of RPhTs to conduct BPMHs therefore complements pharmacists' roles in reconciling and providing medication management.

A key learning from this initiative was an appreciation of the time and resources required to effectively and efficiently implement patient safety programs within health care institutions. Successful implementation of the $\mathrm{RPhT}$-conducted BPMH program required training of the RPhTs, development of new tools, ongoing communication with our interprofessional team, data collection, and iterative changes to workflow. As such, time constraints were a significant barrier to BPMH compliance. In addition, having one pharmacist oversee both the PAC (i.e., training RPhTs, auditing BPMHs, addressing BPMH-related issues) and postoperative unit (i.e., performing medication reconciliation before discharge) posed logistical challenges, as there were occasions when the pharmacist was needed simultaneously in both units.

Another lesson from this project was that consistent communication with members of the health care team is fundamental to ensuring optimal uptake of new programs. In the early stages of the RPhT-conducted BPMH program, one of the barriers to BPMH compliance was low referral of eligible patients to the RPhT. This was attributable to multiple factors: inadequate understanding of the BPMH process, lack of clarity about BPMH eligibility criteria, and slow adaptation to the new workflow. These issues were, however, addressed through constant communication (emails, meetings, reminders) with the staff and leaders of the interprofessional teams.

A third important lesson involved patients whose medications were not covered through the provincial insurance program, for whom the RPhTs were unable to obtain a preliminary list of medications before the BPMH interviews. In addition, a number of these patients did not bring their medication vials to the PAC. As such, the RPhTs were only able to verify medication information with their community sources (e.g., pharmacies, nursing home) after the interview was completed (i.e., after source contact information was obtained). This led to inefficiencies, such as having to phone the patient back at the end of the day to clarify any discrepancies identified. Since it was not possible to reach patients at all times, this retrospective approach to addressing discrepancies impeded completion of the BPMH. It might have been helpful in this situation to have hospital volunteers call patients ahead of their PAC visits to gather community pharmacy information and remind the patient to bring their medication vials. This would have allowed the RPhT to contact the pharmacy before the BPMH interview so that any discrepancies could be addressed during the interview.
One limitation of this project was that the BPMHs were not audited for medication discrepancies. The pharmacist audited the BPMHs to ensure that all required information had been gathered and documented. The pharmacist also checked for accurate spelling of medication names, use of appropriate units, and use of dangerous abbreviations. However, the pharmacist did not access the secondary sources (e.g., community pharmacy-generated lists) to verify the information that the RPhT had documented. Doing so would have enabled the pharmacist to assess the comprehensiveness (e.g., identifying errors of omission) and accuracy (e.g., correct doses) of RPhT-conducted BPMHs.

Another limitation was lack of validation of the criteria used to select patients who might be suitable for medication reconciliation by a pharmacist at the time of discharge. These criteria were developed using literature information about high-risk medications $\mathrm{s}^{20-22}$ and consensus among the interprofessional team regarding patients who would most benefit from medication reconciliation upon discharge.

Future projects could expand on this work by identifying discrepancies in RPhT-conducted BPMHs to further assess their training and competency in fulfilling this role. Identifying such discrepancies would also assist with the development of strategies to address them according to the level of severity (e.g., omission of a prescription medication versus omission of a vitamin or supplement). In addition, future work could explore patients' views and experiences of RPhT-conducted BPMH, to gain insight into the perceived acceptability and impact of this model on their care.

\section{CONCLUSION}

Overall, this project demonstrated that RPhT-conducted BPMHs can improve compliance with BPMH practices within ambulatory care. Future evaluation efforts could focus on exploring patients' experiences with this model and determining how RPhT-conducted BPMH can help to improve the overall medication reconciliation process.

\section{References}

1. Medication reconciliation in acute care: Getting started kit. Version 3 Safer Healthcare Now; 2011 [cited 2016 Aug 8]. Available from: https:// www.ismp-canada.org/download/MedRec/Medrec_AC_English _GSK_V3.pdf

2. Cornish PL, Knowles SR, Marchesano R, Tam V, Shadowitz S, Juurlink $\mathrm{D}$, et al. Unintended medication discrepancies at the time of hospital admission. Arch Intern Med. 2005;165(4):424-9.

3. Vira T, Colquhoun M, Etchells E. Reconcilable differences: correcting medication errors at hospital admission and discharge. Qual Saf Health Care. 2006;15(2):122-6.

4. Kwan Y, Fernandes OA, Nagge JJ, Wong GG, Huh JH, Hurn DA, et al. Pharmacist medication assessments in a surgical preadmission clinic. Arch Intern Med. 2007;167(10):1034-40.

5. Karnon J, Campbell F, Czoski-Murray C. Model-based cost-effectiveness analysis of interventions aimed at preventing medication error at hospital admission (medicines reconciliation). J Eval Clin Pract. 2009;15(2):299-306. 
6. McCarthy L, Su XW, Crown N, Turple J, Brown TE, Walsh K, et al. Medication reconciliation interventions in ambulatory care: a scoping review. Am J Health Syst Pharm. 2016;73(22):1845-57.

7. MARQUIS Investigators. MARQUIS implementation manual: a guide for medication reconciliation quality improvement. Society of Hospital Medicine; 2014 [cited 2017 Oct 3]. Available from: http:// tools.hospitalmedicine.org/resource_rooms/imp_guides/MARQUIS/ MARQUIS-Guide-2014-Final.pdf

8. Wilson JS, Ladda MA, Tran J, Wood M, Poyah P, Soroka S, et al. Ambulatory medication reconciliation in dialysis patients: benefits and community practitioners' perspectives. Can J Hosp Pharm. 2017;70(6):443-9.

9. Davidson TR, Hobbins MA, Blubaugh CM. Development and implementation of a pharmacy technician medication history program. J Pharm Pract. 2019;:897190019878565.

10. Remtulla S, Brown G, Frighetto L. Best possible medication history by a pharmacy technician at a tertiary care hospital. Can J Hosp Pharm. 2009;62(5):402-5.

11. Fabiilli NA, Powers MF. Roles for pharmacy technicians in medication reconciliation during transitions of care. J Pharm Technol. 2017; 33(1):3-7.

12. Required organizational practices. Accreditation Canada; 2016 [cited 2016 Jun 3]. Available for purchase from: https://accreditation.ca/ required-organizational-practices/

13. Hoffmann TC, Glasziou PP, Boutron I, Milne R, Perera R, Moher $\mathrm{D}$, et al. Better reporting of interventions: template for intervention description and replication (TIDieR ) checklist and guide. BMJ. 2014; 348(1687):g1687.

14. BPMH training for pharmacy technicians [workshop information] Institute for Safe Medication Practices Canada; 2016 [cited 2016 Aug 7]. Available from: https://www.ismp-canada.org/education/ workshops/2019/1122_bpmh/

15. e-BPMH training certification package. Sunnybrook Health Sciences Centre; 2016 [cited 2016 May 12]. Available from: https://sunnybrook .ca/education/content/?page=education-bpmh-training

16. Michels RD, Meisel SB. Program using pharmacy technicians to obtain medication histories. Am J Health Syst Pharm. 2003;60(19):1982-6.

17. Johnston R, Saulnier L, Gould O. Best possible medication history in the emergency department: comparing pharmacy technicians and pharmacists. Can J Hosp Pharm. 2010;63(5):359-65.

18. Leung M, Jung J, Lau W, Kiaii M, Jung B. Best possible medication history for hemodialysis patients obtained by a pharmacy technician. Can J Hosp Pharm. 2009;62(5):386-91.

19. Weber EW, Cohn-Oswald L, Hepfinger C, Kidd G, Koontz R. Clinical pharmacy technicians: a valuable resource for clinical pharmacists. Fed Pract. 2004;21(11):22-32.

20. Engels MJ, Ciarkowski SL. Nursing, pharmacy, and prescriber knowledge and perceptions of high-alert medications in a large, academic medical hospital. Hosp Pharm. 2015;50(4):287-95.
21. Cohen MR, editor. Medication errors. 2nd ed. American Pharmacists Association; 2007.

22. Cohen MR, Smetzer JL, Westphal JE, Comden SC, Horn DM. Risk models to improve safety of dispensing high-alert medications in community pharmacies. J Am Pharm Assoc. 2012;52(5):584-602.

Ida-Maisie Famiyeh, RPh, BScPhm, ACPR, MSc, is with Women's College Hospital, Toronto, Ontario.

Neil Jobanputra, RPh, MPharm, HBSc, was, at the time of this study, with Women's College Hospital, Toronto, Ontario. He is now with HealthPRO Procurement Services Inc, Toronto, Ontario.

Lisa M McCarthy, RPh, BScPhm, PharmD, MSc, was, at the time of this study, with Women's College Hospital, Toronto, Ontario; she is now with the Institute for Better Health and the Pharmacy Department at Trillium Health Partners, Mississauga, Ontario. She maintains her affiliation with the Leslie Dan Faculty of Pharmacy and the Department of Family and Community Medicine, University of Toronto, Toronto, Ontario.

Competing interests: For activities unrelated to the work described here, Lisa McCarthy has received grants from the Canadian Institutes of Health Research, the Canadian Foundation for Pharmacy, the Canadian Society of Hospital Pharmacists Research and Education Foundation, and the Ontario Ministries of Health and of Long-Term Care (through the Ontario Centres for Learning, Research \& Innovation in Long-Term Care at Bruyère, and the Centre for Aging and Brain Health Innovation, Baycrest). She has also received travel funds from the National Health Service (England) to attend a conference and honoraria from MediSystem Pharmacy for a continuing professional development workshop. No other competing interests were declared.

\section{Address correspondence to:}

Dr Lisa M McCarthy

Women's College Research Institute

76 Grenville Street

Toronto ON M5S 1B2

email: lisa.mccarthy@utoronto.ca

Funding: This program was implemented and evaluated through in-kind resources supplied by Women's College Hospital. In addition, the Canadian Society of Hospital Pharmacy (Ontario Branch) presented the authors with the 2018 Bill Wilson Patient Safety Award, which included funds recognizing the work described in the manuscript and to support future program enhancements not described herein.

Acknowledgements: The authors would like to thank the Women's College Hospital Pharmacy and Surgical Services team for their collaboration and invaluable support in implementing the program, particularly Nancy Groff, Mei Lei Ling, Than Vu, Victoria Noguera, Atul Prabhu, and Cristina Barrett. They also wish to thank Tania Parkes, Bosco Kalathiparambil, Bennedict Wallace, and Carmen Beligan, registered pharmacy technicians, for their efforts in making this program a success, and Miles Luke for supporting data analysis. Finally, the authors thank the Canadian Society of Hospital Pharmacists (Ontario Branch) for recognizing this project through the 2018 Bill Wilson Patient Safety Award. 